\title{
O que as crianças dizem sobre a escola?
}

\author{
What do children say about school?
}

\section{¿Qué dicen los niños sobre la escuela?}

\author{
* Adriana Regina de Jesus Santos \\ Doutora pela Universidade Estadual de Londrina, Londrina, Paraná, Brasil \\ adrianatecnologia@yahoo.com.br
}

Recebido: 17 de março de 2018

Aprovado: 19 de outubro de 2018

\section{RESUMO}

Compreender o que seja a escola na formação do pensamento simbólico dos alunos é o nosso desafio. Sendo assim, o presente artigo tem como objetivo perceber a infância por meio do olhar da criança de modo a levar em conta a alteridade da mesma, legitimando-a como ser capaz de refletir ao narrar suas vivências e, por essa via, trazer informações importantes sobre as escolas da infância e sobre a criançasujeito. Para tanto, foi realizada uma pesquisa de campo com alunos da Educação Infantil e Anos Iniciais de um colégio estadual localizado na cidade de Londrina, Paraná, tendo como objetivo compreender a percepção das crianças de 4 a 10 anos de idade a respeito da escola e de sua funcionalidade na formação e aprendizado humano. Em relação à metodologia de trabalho, este estudo se pautou na pesquisa bibliográfica e de campo, usando como parâmetro a abordagem qualitativa, que utilizou a narrativa como um instrumento de coleta de dados. Ao término da pesquisa, pôde-se constatar que a escola precisa ressignificar o seu tempo e espaço escolar, possibilitando ao aluno a capacidade de construir e transformar, de forma independente, a atividade da própria vida, ser seu verdadeiro sujeito social, tecendo um olhar urgente para a própria transformação do espaço do aprender que ainda se detém a uma organização que não permite a interação e o diálogo em favor do conhecimento e da formação humana.

Palavras-chave: Escola; Infância; Diálogo; Formação humana.

\section{ABSTRACT}

Understanding what school is in the formation of the symbolic thought of the students is our challenge. So the present article aims to perceive childhood through the child's gaze so as to take into account the otherness of the same, legitimizing it how to be able to reflect when narrating their experiences and for this way to bring important information about the schools of childhood and about the child-subject. For that, a field research was carried out with students from Early Childhood Education and Early 


\section{T Lism Eutthab̧a}

DOI: $10.5902 / 1984644429624$

Years of a state college located in the city of Londrina, Paraná aiming to understand the perception of children from the ages of 4 to 10, regarding school and Functionality in human training and learning. In terms of the methodology of work, this study was based on bibliographical and field research, having as parameter the qualitative approach, which used the narrative as an instrument of data collection. At the end of the research, it can be verified that the school has to re-signify its school time and space, allowing the student the capacity to independently construct and transform the activity of one's own life to be its true social subject the very transformation of the learning space that still stands to an organization that does not allow interaction and dialogue in favor of the human knowledge and formation.

Keywords: School; Childhood; Dialogue; Human formation.

\section{RESUMO}

Comprender lo que sea la escuela en la formación del pensamiento simbólico de los alumnos es nuestro desafío. Siendo así, el presente artículo tiene como objetivo percibir la infancia por medio de la mirada del niño para tener en cuenta la alteridad de la misma, legitimándola como ser capaz de reflexionar al narrar sus vivencias y, por esa vía, traer informaciones importantes sobre las escuelas de la infancia y sobre el niño sujeto. Para ello, se realizó una investigación de campo con alumnos de Educación Infantil y Años iniciales de un colegio estadual ubicado en la ciudad de Londrina, Paraná, teniendo como objetivo comprender la percepción de los niños de 4 a 10 años de edad respecto a la escuela y de la escuela su funcionalidad en la formación y el aprendizaje humano. En relación a la metodología de trabajo, este estudio se basó en la investigación bibliográfica y de campo, usando como parámetro el abordaje cualitativo, que utilizó la narrativa como un instrumento de recolección de datos. Al término de la investigación, se pudo constatar que la escuela necesita resignificar su tiempo y espacio escolar, posibilitando al alumno la capacidad de construir y transformar, de forma independiente, la actividad de la propia vida, ser su verdadero sujeto social, tejiendo una mirada urgente para la propia transformación del espacio del aprendizaje que aún se detiene a una organización que no permite la interacción y el diálogo a favor del conocimiento y de la formación humana.

Palavras-chave: la escuela; la infancia; diálogo; Formación humana.

\section{Introdução}

Este ensaio teórico surge com o objetivo de refletir sobre as narrativas das crianças em relação ao significado da escola, motivadas pela percepção social do 


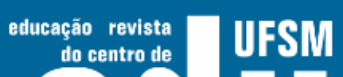

DOI: $10.5902 / 1984644429624$

que se está sendo construída no cotidiano escolar, em relação à criança e à escola, muitas vezes numa percepção de não inteireza dessas.

Justifica-se trabalhar com as narrativas por se entender que "quanto mais formos capazes de nos dar conta e de dar conta aos outros da experiência vivida, mais ela será vivida conscientemente." (VYGOTSKY, 2003, p. 78).

Dessa forma, buscou-se repensar a escola enquanto processo educativo crucial na construção de novas relações pedagógicas orientadas para a produção de novas formas de cidadania, autoconhecimento e autocrítica nela envolvidos. Diante disso, conforme se processam as mudanças nos âmbitos político, social, econômico e cultural, a educação também é alterada, refletindo de maneira significativa no contexto escolar propriamente dito. A educação escolar expressa essas mudanças mais amplas em seu cotidiano e, em muitos casos, se adequa às novas demandas sociais. Portanto, torna-se imprescindível compreender a escola sob a perspectiva de alunos entre quatro a dez anos de idade.

A proposta visa a olhar a infância de modo a levar em conta a alteridade da criança, legitimando-a como ser capaz de refletir ao narrar suas vivências e, por essa via, trazer informações importantes sobre as escolas da infância e sobre a criançasujeito. Isto posto, a reflexividade na infância, sobre a qual se baseia o texto, permeia as reflexões deste trabalho e vai ao encontro das investigações realizadas nos últimos anos do século XXI por pesquisadores preocupados em conferir à criança o estatuto de sujeito de direito, conforme atestam as publicações mais recentes nessa área. Justifica-se a importância desse tema também por entender, segundo Larrosa (2010, p. 184), que a infância desestabiliza "a segurança de nossos saberes, questiona o poder de nossas práticas e abre um vazio em que se abisma o edifício bem construído de nossas instituições de acolhimento".

Este trabalho foi organizado em duas partes: na primeira, definiu-se o quadro teórico e metodológico da pesquisa; na segunda, tematizou-se como as crianças da Educação Infantil e Anos Inicias do Ensino Fundamental percebiam a escola e sua funcionalidade. 


\section{Aillbapẫ

\section{O caminho percorrido}

DOI: $10.5902 / 1984644429624$

Para o desenvolvimento deste estudo, foi realizada uma pesquisa de campo com alunos de um colégio estadual localizado na cidade de Londrina, Paraná com o objetivo de compreender a percepção de crianças de 4 a 10 anos de idade a respeito da escola e de sua funcionalidade na formação e aprendizado humano.

Nesse sentido, pensar a cultura escolar na contemporaneidade é o objeto dessa reflexão. Conhecer como se dá essa lógica no processo de aprendizagem e representação do que seja a escola na formação do pensamento simbólico dos alunos é o desafio de se compreender a visão que se tem da escola.

Com relação à metodologia de trabalho, vale considerar que este estudo se pautou na pesquisa bibliográfica e de campo, tendo como parâmetro a abordagem qualitativa, que utilizou a entrevista como um instrumento de coleta de dados. No que tange à realidade social dos alunos, estes são filhos de funcionários e/ou residem na comunidade próxima ao Campus Universitário, tendo seus pais formação variada, tais como professores da Educação Básica e Educação Superior, funcionários técnico-administrativos, representantes de chefia e cargos administrativos da Instituição de Ensino, operários, funcionários de serviços gerais, desempregados, entre outros.

Faz-se necessário ressaltar a opção metodológica de análise das narrativas dos alunos por se tratar, sobretudo, da necessidade de ultrapassar o nível da constatação sobre o que se passa "na cabeça" dos sujeitos envolvidos procurando compreender como e por que essas percepções, atribuições, atitudes e expectativas são construídas e mantidas recorrendo aos sistemas de significação socialmente enraizados e partilhados que as orientam e justificam.

Assim, analisar a escola levando em consideração as narrativas dos alunos colabora para compreender as transformações pelas quais essa instituição escolar vem passando ao longo da história da educação, bem como tem sido constituído o seu papel social na contemporaneidade. Nesse sentido, a intenção é desenvolver uma reflexão teórico-metodológica que contemple as leituras e interpretações sócio históricas que os alunos fazem em relação à escola. 


\section{F WFH

DOI: $10.5902 / 1984644429624$

Desse modo, é importante considerar que os processos educacionais são mecanismos culturais de desenvolvimento que introduzem novas funções alterando o curso dos processos naturais. A relação pedagógica em contextos formalizados como a escola, onde a intencionalidade educativa está claramente presente, é sempre uma relação que promove a reelaboração e a reflexão do sujeito cultural pela introdução de novas leituras no campo dos processos psicológicos e simbólicos. É nesse sentido que se vê a necessidade de analisar a leitura dos alunos acerca da escola da infância.

Vygotsky (1989) afirma que os sistemas simbólicos e subjetivos, particularmente a língua (comunicação), exercem um papel fundamental na comunicação entre os sujeitos e no estabelecimento de significados compartilhados que permitem a interpretação dos objetos, eventos e situações do mundo real.

A recolha dos dados da pesquisa aconteceu no ano de 2016 e a escolha da faixa etária de 4 a 10 anos de idade se deu no sentido de se buscar compreender a criança em seu duplo estatuto: o de criança pequena que ingressa num mundo da cultura mais diversificada do que o da família; e do aluno na interação com o mundo cultural da escola, considerando-o como sujeito de sua formação intelectual e pessoal. (SACRISTÁN, 1999).

Para tanto, a coleta de dados se deu por meio de uma roda de conversa com, no máximo cinco crianças, e, no mínimo três, assim distribuídas: Grupo $1 \neg-$ crianças de 4 a 5 anos; Grupo 2- crianças de 5 a 6 anos; Grupo 3- crianças de 7 a 8 anos; Grupo 4- crianças de 9 a 10 anos. Participou da pesquisa um total de vinte crianças. As rodas de conversa foram gravadas em áudio por meio de desenhos e posteriormente transcritas.

A roda de conversa foi organizada em função da presença de um pequeno "alienígena" que vem visitar a escola, representado por um boneco de tecido, semelhante a um sapinho. A ideia do "alienígena" se deu em virtude de provocar nas crianças a imaginação e a ludicidade, o que foi possível constatar por meio das falas das crianças, pois todas gostaram muito de conhecer o "alienígena". Elas conversaram por horas com ele, narrando o que entendiam sobre a escola e sua funcionalidade. 


\section{工保W

DOI: $10.5902 / 1984644429624$

Faz-se necessário ressaltar que, todo início da roda de conversa, era apresentado o "alienígena" dizendo: "Este é um pequeno alienígena que mora num planeta onde não tem escolas e veio aqui porque queria que vocês contassem para ele tudo o que vocês sabem sobre a escola. Quem gostaria de explicar para o pequeno extraterrestre como é a escola? Para que serve a escola? O que a gente faz aqui?".

Para a fase de desenvolvimento, foram previstas algumas perguntas para explorar a percepção da criança, entre elas: "O que é uma escola? O que mais gosta da escola? O que você não gosta da escola?" Entre outras questões. Foi solicitado aos alunos também que desenhassem como viam a escola e, por meio dos desenhos, foi possível coletar informações muito significativas. Nas análises, buscou-se mapear as percepções dos estudantes que emergiram nas rodas de conversas de acordo com os grupos de crianças, como será visto a seguir.

\section{Grupos 1 e 2- a escola como espaço do brincar e da fantasia}

As crianças participantes do Grupo 1 da Educação Infantil representam uma faixa etária de 4 a 6 anos de idade e estes percebem a escola como um espaço da brincadeira, ludicidade e, principalmente, espaço para o descobrimento. Sendo assim, quando foi perguntado o que entendiam e o que mais gostavam da escola, responderam que:

A escola é um lugar que aprende várias coisas. (Vitor, 4 anos).

Lugar de brincar muito. (Arthur, 4 anos).

Gosto muito da escola. O que eu mais gosto na minha escola é brincar com os amigos. Gosto de brincar. Aqui na escola eu brinco de carrinho, balanço e casinha. (Vitor, 4 anos).

Gosto de fazer atividade. Fazer atividade é desenhar, pintar. É o que faço na escola. Eu desenho o que a professora manda desenhar. Quando a professora dá atividade de pintar é bem legal, gosto de pintar as atividades. Eu gosto da escola. O que eu mais gosto é brincar com os amigos. Gosto de brincar com os brinquedos e de bola. (Arthur, 4 anos).

Gosto de brincar porque a gente se diverte. Quando a gente está alegre, a gente grita. (Maria Eduarda, 4 anos).

Eu gosto do baú do tesouro. Achamos um baú aqui na escola, e tinha muito ouro dentro dele. Brincamos bastante com o ouro do baú e depois a professora levou a gente na padaria e compramos um picolé. Por isso gosto muito da escola. (Maria Eduarda, 4 anos). 


\title{
W WEM efituará
}

DOI: $10.5902 / 1984644429624$

Tendo como parâmetro as falas acima, é possível dizer que os alunos relacionam a escola como um espaço que promove brincadeiras, aprendizado e fantasia, e estes aspectos influenciam e implicam de maneira significativa no processo de ensino e aprendizagem. Segundo Vigotsky (1984, p. 32),

\begin{abstract}
É na brincadeira que a criança consegue vencer seus limites e passa a vivenciar experiências que vão além de sua idade e realidade, fazendo com que ela desenvolva sua consciência. Dessa forma, é na brincadeira que se pode propor à criança desafios e questões que a façam refletir, propor soluções e resolver problemas. Brincando, elas podem desenvolver sua imaginação, além de criar e respeitar regras de organização e convivência, que serão, no futuro, utilizadas para a compreensão da realidade.
\end{abstract}

Ou seja, o brincar e o lúdico promovem o autoconhecimento, propiciando o desenvolvimento físico-motor, bem como o raciocínio e a inteligência. Ao brincar, a criança sempre se comporta além do que é habitual para a sua idade, provocando, assim, a ida ao mundo da imaginação e das possibilidades, o que pode acarretar na construção de sua autonomia, ou seja, seu autogoverno.

Contribuindo com essa reflexão, em seu livro sobre Baudelaire, Sartre cita um trecho que vem ao encontro deste processo de autonomia e de autoconhecimento, quando afirma que: "Fadigada desse brinquedo, Emily, caminhava sem rumo em direção à popa, quando de repente, lhe veio o pensamento fulgurante de que ela era ela." (SARTRE, 1947, p. 147).

Portanto, as brincadeiras e a fantasia na escola permitem à criança buscar se conhecer, como fez Emily, no romance descrito acima, as quais a possibilitaram de conhecer quem é ela nesse cenário social. Sendo assim, o lúdico e o brincar são das principais linguagens da infância e são indispensáveis para o desenvolvimento humano, tendo em vista que para a criança que brinca, o brincar é carregado de significados que extrapolam, muitas vezes, a compreensão "adultocêntrica" que tende a explicar as situações e acontecimentos do cotidiano de forma ortodoxa. Isto posto, a escola da infância necessita entender que, ao brincar, a criança se sente livre para expressar seus sentimentos e analisar os fatos do cotidiano sob sua ótica infantil. 


\title{
OF HW elturarao

DOI: $10.5902 / 1984644429624$

No decorrer das conversas e utilizando o ET como um recurso de linguagem, perguntou-se o que os alunos não gostavam da escola. Noventa por cento dos alunos afirmaram que não gostavam da "Hora do Soninho", como explicitado abaixo:

\begin{abstract}
Eu só não gosto da hora da soneca. Não gosto de dormir na escola. Gosto de brincar. Queria brincar mais. (Arthur, 4 anos).

Não gosto da soneca. A professora coloca a gente para dormir. E eu não gosto de ficar dormindo na escola. Mas de tanto ela falar eu acabo dormindo. Mas depois não consigo dormir em casa. Ao invés de dormir na escola, podíamos brincar, é mais gostoso. (Maria Eduarda, 4 anos).

Não gosto de dormir na escola. Acho que a professora podia fazer o seguinte: quem quiser dormir dorme, e quem não quer dormir podia ficar brincando com os jogos ou lendo alguma coisa. (Felipe, 5 anos).
\end{abstract}

Alguns autores, tais como Batista (1998), Coutinho (2002) e Coelho (2009), apontam a "hora do sono" como importante para a criança na Educação Infantil, pois ela possibilita momentos tranquilos de descanso para criar um intervalo na agitação do dia a dia da escola.

No entanto, ao ouvir os alunos, percebe-se que talvez este momento de tranquilidade seja para os adultos, e não para eles. Ou seja, o espaço escolar poderia pensar em outras estratégias, tais como experimentar a tranquilidade lendo (ou manipulando) livros, montando jogos de construção ou até desenhando ou criar cantos com propostas que não promovesse a agitação. Assim, os que quisessem dormir, poderiam dormir e os outros poderiam buscar o momento de relaxamento com outros tipos de atividades, descaracterizando, desta maneira, a "Hora do Soninho" como um momento autoritário e homogêneo, o qual desrespeita o ritmo de cada aluno.

Diante disso, o professor poderia explicar para o aluno a importância da hora do relaxamento, ou seja, informando que este é um momento em que é preciso falar baixinho e não fazer barulho para não acordar os amigos que fizeram a opção por dormir. Com isso, o aluno vai construindo o entendimento sobre essa rotina. Outra estratégia interessante se refere à contação de histórias, pois, por meio dela, os alunos podem ficar mais tranquilos e, assim, com o passar dos dias, aqueles que não dormem vão se deixar contagiar pela atmosfera sossegada e instigante provocada pelo mundo da leitura. Tudo isso sem forçar a natureza de cada indivíduo.

Em relação às professoras (neste espaço formativo, todas eram do gênero feminino), os alunos foram unânimes em dizer que gostavam muito, pois as mesmas 


\section{$\sim$

DOI: $10.5902 / 1984644429624$

brincavam com eles o tempo todo. A relação professor-aluno é de extrema importância, pois, segundo Goldani (2010, p. 29):

O professor precisa ter sensibilidade e esta deve estar presente em um olhar, um gesto, um diálogo de modo que integre à visão do aluno, fazendoo compreender a sua realidade. O educador sensível é aquele que questiona suas ações baseando-se na abordagem que a criança faz da realidade, verbalizando uma realidade vista a seu modo, com suas capacidades estruturais, funcionais e afetivas. A sensibilidade do professor torna-o capaz de entender os estágios de desenvolvimento da criança, fazendo-o vivenciar um mundo de imaginação, sonhos, alegria. $\mathrm{O}$ aluno vê no professor as chances de um caminho mais consistente na busca da realização cognitiva, afetiva, motora e emocional e principalmente esta relação é crucial no processo de transição entre a pré-escola e o Ensino Fundamental.

Faz-se necessário ressaltar que a transição entre a pré-escola e o Ensino Fundamental é um momento significativo na vida das crianças. Diversos estudos, dentre eles Moss (2002), Rosemberg (2004), Kramer (1992) e Teixeira (2008), buscam compreender os significados da transição entre os distintos espaços de socialização da criança. Este processo de transição foi algo que foi observado por meio das falas das crianças pertencentes aos Grupos 3 e 4.

\section{Grupos 3 e 4- a travessia: passagem da Educação Infantil para os Anos Iniciais}

Ao conversar com as crianças de 6 a 10 anos de idade a respeito do significado de escola, as mesmas responderam que:

Não sei falar direito. A gente fica escrevendo. No pré era mais legal, a gente brincava mais. Aqui não brinca muito. A gente fica copiando um monte de palavra. Eu consigo aprender mais ou menos. Quando chego em casa minha mãe me ajuda, pois toda vez que chamo a professora ela fala que está ocupada e não dá tempo de me ensinar. Não gosto quando não consigo aprender. Mas minha mãe falou que logo vou aprender. No pré, eu aprendia as coisas e brincava também; já aqui, a gente nunca brinca, por isso é um pouco chato, queria brincar mais. (Renan, 6 anos).

É aprender a escrever letras. (Fernanda, 7 anos).

Lugar onde aprende a escrever, a ler e contar. (Rogerio, 7 anos).

Um lugar que a gente aprende Português, Matemática, Ciências, História, Educação Física, Arte. (Nathalia, 7 anos).

Um lugar que a gente aprende a contar e escrever. (Leonardo, 8 anos).

Lugar de aprender, mas eu tenho um pouco de dificuldade. Eu não consigo aprender muitas coisas. Fico triste por isso, mas não sei o que fazer. Alguns amigos tiram sarro, mas eu faço de conta que nem ligo, aí eles param. Eu não falo para a professora que tenho dificuldade, pois ela fica brava e grita quando erro. Quando a gente chama ela, ela fala: silêncio e presta atenção no que estou falando! (Renan, 8 anos).

Ah! Não sei. Não sei explicar direito. (Lorena, 8 anos). 


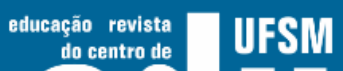 \\ 1SSN: 1984-8444

DOI: $10.5902 / 1984644429624$

Lugar que a gente consegue aprender a escrever o nosso nome, ET, e isso é legal. Aprendemos a escrever várias palavras também. (Nathalia, 7 anos). Lugar de aprender a ler e escrever e de fazer contas também. (Lorena, 7 anos).

É um lugar que às vezes é legal e outras não. (Paulo, 8 anos).

Foi possível constatar que o olhar destas crianças em relação à escola é muito diferente das crianças da Educação Infantil. Ou seja, o Ensino Fundamental, para os alunos participantes da pesquisa, é um momento em que se aprende a ler e a escrever e a brincadeira não faz parte do cotidiano.

Assim sendo, percebe-se, por meio das falas dos alunos acerca do espaço e do tempo da escola da infância, a influência da tendência tradicional, isto é, um espaço onde se trabalha a exposição dos conteúdos de forma verbal pelo professor, que é autoridade máxima, não possibilitando, desta maneira, sua interação com o aluno. Isto foi possível de se aferir pelas falas dos alunos quando eles disseram que tinham receio de falar para a professora que estavam com dificuldade em relação ao aprendizado. Tendo como premissa a tendência tradicional, segundo Saviani (1988), os conteúdos são apresentados descontextualizados, não permitindo, assim, a compreensão da realidade social pelo aluno, que assume um papel submisso e passivo sobre o que está posto. O aluno, nesta perspectiva, deve se empenhar para atingir êxito pelo próprio esforço.

A educação, nesta concepção tradicional, segundo Herbart (1983), é entendida como processo externo e prevalece somente a transmissão fragmentada do conhecimento, sendo a escola centrada na formação moral e intelectual. Dessa forma, é hierarquizada com normas rígidas de disciplina e imposição de valores morais e de condutas. Em suma, caracteriza-se pela perspectiva conteudista, exercícios de fixação e memorização. Por isso, Saviani (1988) classifica o método tradicional como intelectualista e enciclopédico, visto que trabalha os conteúdos separadamente da experiência do aluno e das realidades sociais.

Contribuindo com esta reflexão, os alunos do Ensino Fundamental afirmaram que aprender é:

Saber o que a professora fala. A professora fala, depois escreve no quadro e pede para a gente copiar, é isso. (Leonardo, 8 anos).

Aprender é aprender a escrever e ler. (Leticia, 8 anos). 


\section{工 Wusm ElturahaO}

DOI: $10.5902 / 1984644429624$

A professora briga e grita quando a gente erra alguma coisa. Quando ela fala, eu fico prestando atenção para aprender. (Fernanda, 7 anos).

O processo de ensino e aprendizagem representado nas falas dos alunos leva a percepção da inexistência do diálogo, bem como da mediação no contexto da sala de aula, quando afirmam que:

Não gosto de nenhuma matéria, mas eu tenho facilidade de aprender. Tiro só nota dez. Eu não gosto dos professores, porque eles gritam muito. São chatas. Elas ficam gritando. A professora quando está dando aula de Português, fala assim: Não pega o seu lápis, pega sua caneta! Aí no outro dia ela grita: não pega a caneta, pega o lápis! A minha cabeça até dói, de tanto que ela grita. Não gosto de ficar ouvindo a professora gritar, por isso é mais gostoso brincar com os colegas. (Renan, 8 anos).

Ah! Eu não gosto de prova. A professora de Educação Física dá prova surpresa. É muito chato. Ela explica as mesmas coisas que a gente aprendeu no $2^{\circ}$ ano. Se a gente faz uma baguncinha ela não deixa a gente ir para o intervalo. Ficamos trancados na sala de aula. Ela fala assim: vamos ficar aqui dentro da sala, e fala gritando! (Leticia, 8 anos).

Os dizeres acima remetem, antes de discutir os saberes e práticas docentes, nesse contexto atual, primeiramente ao processo de se tornar professor, ou seja, como tem sido constituída a referência social e pedagógica desse profissional. Tornar-se professor constitui-se de um processo complexo, idiossincrático e multidimensional que implica o aprender a ensinar e a socialização profissional decorrente da interação entre o indivíduo e o contexto, bem como a construção da identidade profissional.

Muitas vezes, esse profissional está ora limitado ao "fazer", com a operacionalização técnica de conceitos e atividades sem conhecimento e sem uma apropriação teórica que venha subsidiar sua prática docente, sem compreensão crítica desse fazer, ora se tem profissionais marcados pelo saber - conhecimento que não tem provocado a ação, ou seja, há um conhecimento coerente, mas que não se aplica ao cotidiano escolar, emancipado somente pelo discurso, mas não pela ação. É relevante a discussão dessa temática, uma vez que essa análise pode orientar a organização de práticas voltadas ao desenvolvimento humano na escola da infância e, também, possibilitar uma crítica dos saberes e práticas docentes equivocadas existentes no cotidiano escolar. 


\section{F WFH \\ ISSN: $1984-6444$ \\ elithabal}

DOI: $10.5902 / 1984644429624$

A atividade docente, assim como toda atividade do homem moderno, se transformou em mera técnica ou aplicação de conhecimentos produzidos pelas ciências da educação, atendendo à necessidade social de aumento da eficiência, da demanda de qualificação profissional e dos padrões de consumo e do pensamento. Mera atividade repetidora, incapaz de se traduzir em experiências narráveis do conhecimento que possam contribuir com a mediação do professor no que se refere ao processo de ensino e aprendizagem. Este aspecto foi ressaltado pelos alunos quando eles relataram que os professores gritavam o tempo todo na sala de aula, o que leva a pensar que, para estes alunos, os Anos Iniciais são representados apenas pelo grito, enquanto na Educação Infantil, a relação era pautada na ludicidade e no diálogo.

Destarte, é imprescindível articular o embate acerca do saber e da constituição do conhecimento em sala de aula por meio da mediação do conhecimento pelo professor. Para isso, é necessário, enquanto professores, estabelecer uma relação social dinâmica e mediadora, uma vez que, na escola, pode-se desenvolver o pensamento amparado por questões ricas e verdadeiramente criativas de interação social. Isso permite acreditar que, independentemente da faixa etária de desenvolvimento infantil, a criança precisa aprender a interagir socialmente com o mundo, com a cultura e com as pessoas. Parte-se da premissa de que tudo aquilo que a criança aprende com o adulto ou com outra criança mais experiente vai sendo elaborado e incorporado por ela, fazendo com que seus modos de agir e pensar sejam transformados.

As falas dos alunos participantes da pesquisa ressaltam que os mesmos não estão muito satisfeitos no que se refere ao espaço e tempo da escola nos Anos Iniciais do Ensino Fundamental. Sendo assim, foi questionado o que eles mudariam na escola, e eles responderam que:

Podia parar de copiar texto. A gente copia muito texto. A professora sempre pede para a gente copiar as coisas. (Gabriele, 10 anos).

Eu gosto de correr, brincar de futebol. A escola podia deixar a gente brincar mais. Eu gosto da escola, mas às vezes é chata, pois a gente não brinca. (Kaue, 10 anos).

A professora podia ensinar a gente, mas ela não tem tempo para ajudar a gente. Aí eu tenho que aprender sozinha. (Ala, 10 anos). 


\section{W WEM Ellubahá}

DOI: $10.5902 / 1984644429624$

Por meio dessas percepções dos alunos acerca do que mudariam na escola, pode-se afirmar que muitos professores desenvolvem ações que se distanciam da construção do pensamento crítico, submetendo-se às ações voltadas à racionalidade técnica do pensamento e se distanciando de um projeto de formação humana com vistas à emancipação do sujeito e autocrítica, pois fica evidente a não mediação do professor no que se refere ao processo de ensino e aprendizagem, implicando em uma aula sem questionamento, sem poesia, sem imaginação, sem ludicidade e desinteressante.

Nesse processo, só resta ao professor o papel de "explicador" de saberes. Por mais que se tenha como meta o pensamento reflexivo e transformador, a autoridade pedagógica é subjugada por esse processo naturalizado que domina e expropria nossa capacidade criadora, reflexiva e criativa. Com isso, o que deveria ser processo de estranhamento, torna-se, pela ausência da criticidade e da imaginação, algo naturalizado. Nesse sentido, é imprescindível pensar que, se a função da educação se apresenta ainda como a de promover a emancipação, faz-se, então, necessário que esse profissional de Educação desenvolva ações críticas em situações de aprendizagem em espaços formativos.

Um aluno, chamado Eduardo (10 anos), olhou para o ET e disse:

$E T$, você vai aprender coisas aqui na escola, viu. As professoras aqui são disciplinadas e podem te ensinar. Mas você tem que se comportar. Tem horário para tudo. No final, a gente consegue aprender. (Eduardo, 10 anos).

A fala acima remete ao pensamento de que a escola precisa ressignificar o seu tempo e espaço por meio do desenvolvimento de um programa educacional, tendo como parâmetro a formação humana. Ela deve propiciar ao aluno a capacidade de construir e transformar, de forma independente, a atividade da própria vida, ser seu verdadeiro sujeito social, tecendo um olhar urgente para a própria transformação do espaço do aprender que ainda se detém em uma organização que não permite a interação e o diálogo em favor do conhecimento. Ousa-se afirmar sobre a necessidade de permitir uma organização espaço-temporal do ensinar e aprender em que a pessoa se defina no mundo da vida, tenha diversas formas de interação com outras pessoas, se envolva em vários tipos de atividades existentes e crie novas. 


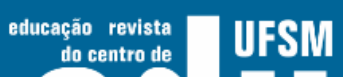 Ellloahá}

DOI: $10.5902 / 1984644429624$

Ora, a escola que se tem deve permitir o seu próprio entendimento, enquanto espaço de organização de um programa educacional diferenciado e inovador, aonde a aprendizagem vá além da transmissão de conhecimento e com o intuito de envolver os alunos em diversas experiências do ensino. Cabe ressaltar que a mediação do professor se faz imprescindível nesse processo a fim de que se construam parâmetros de superação do que está posto, possibilitando, assim, um projeto de formação humana e a ampliação do conhecimento pelo aluno. Ou seja, é crucial pensar no trabalho pedagógico em que haja planejamento e ação coletiva dos envolvidos a fim de que seja possível uma comunicação que permita troca de informações precisas e compartilhamento de significações. No trabalho coletivo, desenvolve-se também o pensamento coletivo e, portanto, as relações sociais, bem como a criação e utilização de instrumentos, ampliando as possibilidades de transformação do saber de maneira lúdica e contextual.

Partindo do pressuposto de uma análise mais ampla do que seja a escola nesse cenário atual, percebe-se que, muitas vezes, ela assume um papel submisso e de reprodução servil da sociedade capitalista, criando em seu interior, culturas que extrapolam o que deve ser seu papel. Em contrapartida, há escolas sucateadas pelo tempo, não avançando significativamente no campo epistemológico, estrutural, metodológico e, acima de tudo, curricular.

Pela importância e significado dessa nova relação para a compreensão do desenvolvimento humano como processo de humanização e pelas implicações inovadoras que essa relação aprendizagem-desenvolvimento tem para as práticas educativas, vale a pena retomar sua explicitação de maneira a considerar que a escola que se quer e acredita deve ser revolucionária no plano do pensamento, a fim de que profissionais preparados possam superar a prática docente descontextualizada, em favor do projeto de conhecimento emancipatório via escola. Segundo Varela (2002), a escola tem que ser um lugar de admiração e de prazer.

É necessário e urgente pensar no papel do professor como mediadores, principalmente neste momento de transição entre Educação Infantil e Anos Iniciais do Ensino Fundamental, pois os alunos, neste processo, segundo os relatos dos sujeitos envolvidos nesta pesquisa, vivenciam uma ruptura drástica. Ou seja, na 


\section{W WEM Eullathá}

DOI: $10.5902 / 1984644429624$

Educação Infantil, a escola é interessante porque é lúdica, e, nos Anos Iniciais, a escola não se torna atrativa, pois faltam o brincar, a imaginação, o diálogo e o acolhimento. Neste sentido, é necessário construir novas leituras e paradigmas que possam expressar a escola enquanto espaço de ludicidade, de construção, de emancipação e de formação para a cidadania, podendo, desta maneira, pensar em uma política de formação de professores comprometida com valores voltados à emancipação, a formação crítica do sujeito e, principalmente, à formação criativa e imaginativa.

\section{Considerações finais}

Objetivou-se, neste artigo, identificar as percepções dos alunos acerca da escola e, por meio das narrativas das crianças, ficou evidente que é preciso levar em consideração a transição da Educação Infantil para os Anos Iniciais do Ensino Fundamental, pois, para os estudantes, a escola da Educação Infantil é o espaço do brincar e da fantasia, ou seja, é uma escola do acolhimento da infância, o que faz com que os alunos gostem deste espaço. Em relação aos Anos Iniciais do Ensino Fundamental, os relatos dos alunos participantes da pesquisa evidenciaram que se trata de um espaço autoritário e onde não há diálogo, prevalecendo, desta maneira, o ensino baseado na memorização e repetição. Sendo assim, tendo como parâmetro a percepção dos alunos, é necessário que a escola investigada pense em uma práxis pedagógica voltada ao pensamento em favor da consciência crítica e da autodeterminação no espaço formativo.

Para isso, a reflexão maior é perceber como tem sido constituído o conhecimento na escola frente às mudanças sociais mais amplas, para assim buscar encaminhamentos por meio dos saberes e das práticas docentes em favor da superação dessa lógica que silencia e empobrece o pensamento humano. Nesse sentido, que marcas a escola está produzindo nos alunos dos Anos Iniciais do Ensino Fundamental? Marcas de emancipação ou conformação?

Tendo em vista os relatos dos alunos dos Anos Iniciais, são marcas de conformação. Portanto, é imprescindível rever este estado de conformação, pois esta é uma prática silenciada e esvaziada de conteúdos que se esgota na própria 


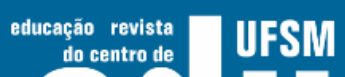 \\ ISSN: $1984-6444$ \\ elithabal}

DOI: $10.5902 / 1984644429624$

relação formal com o conhecimento, impedindo que forneça ao professor formas para refletir sobre os problemas que enfrenta e para encontrar meios de solucionálos, ou mesmo traduzi-los como experiência.

Isto posto, é necessário que a transição da Educação Infantil para o Ensino Fundamental seja pensada de maneira mais humanizante, sem se esquecer de que o lúdico e as brincadeiras precisam fazer parte da ação pedagógica, pois os alunos da Educação Infantil, quando narraram o que pensavam acerca da escola, fizeram isso de maneira alegre e radiante. Infelizmente os alunos do Ensino Fundamental relataram que a escola poderia ser mais alegre e mais lúdica.

Faz-se necessário ressaltar a urgência do diálogo na organização do sistema educacional brasileiro em relação à Educação Infantil e à Educação Básica. Contribuindo com essa reflexão, Magda Soares (2004, p. 275) afirma que:

\footnotetext{
poderíamos pensar em práticas educativas na educação infantil e no ensino fundamental em que houvesse um "brincar letrando" ou um "letrar brincando", em direção ao estabelecimento de uma relação de parceria entre esses segmentos da educação básica.
}

Assim sendo, o desafio é ressignificar o cotidiano escolar, levando em consideração as narrativas das crianças, ou seja, é preciso desenvolver a "Pedagogia da Escuta", isto é, as crianças conhecem a escola em sua inteireza e esse conhecimento pode ser fundamental na práxis pedagógica. Portanto, o desafio, enquanto profissionais da Educação, é pensar a experiência formativa, apreendida em seu sentido emancipatório e lúdico como possibilidade de resistência ao saber instituído, assim como sobre a sua experiência na infância, no hiato que permanece entre o pensamento e a linguagem, naquilo que ainda não se encontra pronto e acabado para ser comunicado em termos linguísticos e nas suas implicações no trabalho docente.

Nesse embate, o convite é para se repensar o contexto escolar, e que este possa ser percebido pelos alunos como um espaço de formação humana, de valores sociais, do conhecimento crítico e criativo, contribuindo para a formação emancipada e lúdica da criança, pois esta precisa ser entendida como um ser humano histórico, social e em construção. 


\section{DFEM \\ ISSN: 1984-6444

\section{Referências}

DOI: $10.5902 / 1984644429624$

BATISTA, Rosa. A Rotina no dia-a-dia da creche: entre o proposto e o vivido. 1998. 176 f. Dissertação (Mestrado em Educação) - Universidade Federal de Santa Catarina, Florianópolis, 1998.

COUTINHO, Ângela M. Scalabrini. As crianças no interior da creche: a educação e o cuidado no momento do sono, higiene e alimentação. 2002. 164 f. Dissertação (Mestrado em Educação) - Universidade Federal de Santa Catarina, Florianópolis, 2002.

COELHO, Silvia Raquel O. P. Sono e Vigília na Infância: conhecimentos dos educadores. 2009. 135f. Dissertação (Mestrado em Activação do Desenvolvimento Psicológico). Universidade de Aveiro, Portugal. 2009

GOLDANI, Andrea. TOGATLIAN, Marco Aúrelio. COSTA, Rosane de Albuquerque. Desenvolvimento, Emoção e Relacionamento na Escola. Rio de Janeiro: Epapers, 2010.

HERBART, Johann F. Pedagogía general derivada del fin de la educación. Barcelona: Humanitas, 1983.

KRAMER,S. Política do Pré-escolar no Brasil: a arte do disfarce. São Paulo: Cortez, 1992.

LARROSA, Jorge. Tecnologias do Eu e Educação. In: SILVA, Tomaz Tadeu (Org.). O sujeito da Educação: estudos foucaultianos. 7. ed. Petrópolis, Rio de Janeiro: Vozes, 2010.

MOSS, P. Reconceitualizando a infância: crianças, instituições e profissionais. In: MACHADO M. L. de A. (Org.). Encontros e desencontros em educação infantil. São Paulo: Cortez, 2002.

ROSEMBERG, F. Expansão da educação infantil e processos de exclusão. Cadernos de Pesquisa, São Paulo, n. 107, p. 7-40, 2004.

SARTRE, Jean-Paul. Baudelaire. Paris: Gallimard, 1947.

SAVIANI, Dermeval. Escola e democracia. São Paulo: Cortez; Autores Associados, 1988.

SACRISTÁN, J.G. Poderes instáveis em educação. Porto Alegre: Artmed, 1999.

SOARES, Magda. Letramento e Escolarização. In: RIBEIRO, Vera Masagão (Org.). Letramento no Brasil. São Paulo: Global, 2004. 287 p.

TEIXEIRA, T. C. F. Da educação infantil ao ensino fundamental: com a palavra, a criança, 2008. 


\section{ح

DOI: $10.5902 / 1984644429624$

VARELA, Julia. A maquinaria escolar. Teoria e Educação, Porto Alegre, n. 6, p. 6896, 2002.

VYGOTSKY, L. S. Défectologie et déficience mentale, K. Barisniskov e G. Petitpierre, Lausanne: Delachaux et Niestlé, 1989.

VYGOTSKY, L. S. Consciousness as a problem in the psychology of behavior. Tradução de M. Cole, Soviet Psychology, nº 4, p.3-35, 1984.

VYGOTSKY, L. S. Conscience, inconscient, emotions. Paris: La Dispute, 2003.

e Janeiro, 2007.

ZAGAL, J. P. Ludoliteracy: defining, understanding, and supporting games education. Pittsburgh, PA: ETC Press, 2010.

\section{Correspondência}

Adriana Regina de Jesus Santos - Universidade Estadual de Londrina, Rodovia Celso Garcia Cid, Pr 445 Km 380 Cx. Postal 10.011. CEP: 86057-970. Londrina, Paraná, Brasil.

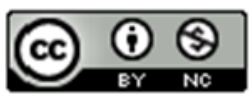

This work is licensed under a Creative Commons Attribution-NonCommercial 4.0 International (CC BY-NC 4.0) 